Research Paper

\title{
Reality and some Factors Related to Treatment Adherence in HIV/AIDS Children at Outpatient Clinic, Vietnam National Children's Hospital
}

\author{
Tran Thi Ngoc*, Do Thien Hai, Tran Thi Duyen, Nguyen Le Chinh \\ Vietnam National Children's Hospital, 18/879 La Thanh, Dong Da, Hanoi, Vietnam \\ Received 11 August 2020 \\ Revised 22 August 2020; Accepted 28 August 2020
}

\begin{abstract}
Purpose: To characterize the prevalence and factors associated with ARV adherence in HIV/AIDS-infected children at outpatient clinics, Vietnam National Children's Hospital.

Methods: A cross-sectional study was conducted at outpatient clinics, Vietnam National Children's Hospital in 2019.

Results: The results showed that $63 \%$ of HIV/AIDS infected children adhered to treatment and $37 \%$ of them did not adhere to ARV. The study investigated the relevance of 11 factors and found 5 factors related to pediatric noncompliance, including a short treatment period of less than 1 year (OR: 17.1; 95\% CI: 2,26-75,5 and $p<0,01$ ); waiting time for taking drugs was too long (OR: 19.3; 95\% CI: 7.9-50.9 and $\mathrm{p}<0.01$ ); main caregivers aged $\geq 50(\mathrm{OR}=42.3 ; 95 \% \mathrm{CI}$ from 17.9-120.1 and $\mathrm{p}<0.01$.

Conclusions: The prevalence of ARV adherence in HIV/AIDS-infected children was $63 \%$. Counseling intervention models to improve drug treatment compliance should be concentrated on newly infected children, treatment duration was less than 1 year and their primary caregivers over 50 years old.
\end{abstract}

Keywords: Adherence to treatment; patients; HIV; ARV.

* Corresponding author.

E-mail address: tranngoc142@gmail.com

https://doi.org/10.25073/jprp.v4i5.224 


\title{
Thực trạng và một số yếu tố liên quan đến tuân thủ điều trị ở trẻ HIV/AIDS tại phòng khám ngoại trú Bệnh viện Nhi Trung ương
}

\author{
Trần Thị Ngọc ${ }^{*}$, Đỗ Thiện Hải, Trần Thị Duyên, Nguyễn Lệ Chinh \\ Bệnh viện Nhi Trung ương, 18/879 La Thành, Đống Đa, Hà Nội, Việt Nam \\ Nhận ngày 11 tháng 7 năm 2020 \\ Chỉnh sửa ngày 12 tháng 8 năm 2020; Chấp nhận đăng ngày 28 tháng 8 năm 2020
}

\section{Tóm tắt}

Mục tiêu: Mô tả thực trạng và phân tích một số yếu tố liên quan tới tuân thủ điều trị ARV của trẻ HIV/AIDS tại phòng khám ngoại trú Bệnh viện Nhi Trung ương.

Phương pháp: Mô tả cắt ngang có phân tích. Trẻ có xét nghiệm khẳng định nhiễm HIV đang điều trị ngoại trú tại phòng khám ngoại trú - Bệnh viện Nhi Trung ương

Kết quả nghiên cứu: Kết quả nghiên cứu cho thấy $63 \%$ trẻ HIV/AIDS tuân thủ điều trị và $37 \%$ trẻ chưa tuân thủ điều trị ARV. Qua phân tích hồi quy đa biến logistic tìm được 3 yếu tố có liên quan đến sự không tuân thủ điều trị của bệnh nhi bao gồm; thời gian điều trị ngắn dưới 1 năm (OR: 17,1;95\% CI: 2,26-75,5 và $\mathrm{p}<0,01)$; thời gian chờ đợi lấy thuốc quá dài (OR: 19,3; 95\%CI: 7,9-50,9 và $\mathrm{p}<0,01)$; người chăm sóc chính có tuổi $\geq 50$ $(\mathrm{OR}=42,3 ; 95 \% \mathrm{CI}$ từ 17,9-120,1 và $\mathrm{p}<0,01)$.

Kết luận: Tỷ lệ tuân thủ điều trị của trẻ HIV/AIDS là $63 \%$; các mô hình can thiệp tư vấn nên được tập trung vào nhóm trẻ mới mắc, có thời gian điều trị dưới 1 năm và bệnh nhi có người chăm sóc chính trên 50 tuổi để nâng cao tỷ lệ tuân thủ điều trị thuốc.

Tù khóa: Tuân thủ điều trị; bệnh nhi; HIV; ARV.

\section{1. Đặt vấn đề}

Điều trị cho người nhiễm HIV/AIDS bằng thuốc kháng retro virus (ARV) [1] giúp chống lại sự nhân lên của virus HIV và kéo dài cuộc sống của người bệnh. Những nghiên cứu gần đây cho thấy điều trị ARV cho người nhiễm HIV là liệu pháp dự phòng lây nhiễm tốt, làm giảm tử vong do AIDS và cả các bệnh liên quan đến AIDS. Duy trì nồng độ thuốc $\mathrm{ARV}$ trong máu nhằm ức chế tối đa sự nhân lên của virus HIV, giúp hệ miễn dịch được phục hồi, từ đó phòng ngừa

"Tác giả liên hệ.

Địa chi email: tranngoc142@gmail.com

https://doi.org/10.25073/jprp.v4i5.224 các bệnh nhiễm trùng cơ hội, cải thiện chất lượng cuộc sống cho người bệnh và tăng tỷ lệ sống sót $[2,3]$.

Tuân thủ điều trị cho trẻ em là một vấn đề phức tạp, bởi trẻ em chưa có đủ nhận thức về bệnh cũng như cách thức điều trị. Mặc dù đã có một số nghiên cứu trong nước và quốc tế về vấn đề tuân thủ điều trị $A R V$ ở trẻ em nhưng trong bối cảnh nguồn lực cho phòng, chống HIV/AIDS chủ yếu dựa vào viện trợ của quốc tế đang cắt giảm nhanh, trong khi các nguồn tài chính trong nước (NSNN, BHYT) chưa kịp bù đắp thiếu hụt tài chính kết hợp với việc chuyển giao các dịch vụ HIV/AIDS từ nhà tài trợ sang cho quốc gia, công tác điều trị được chuyển từ hệ thống dự phòng sang hệ thống điều trị 
ít nhiều thay đổi quy trình, thủ tục hành chính đã phần nào ảnh hưởng đến duy trì điều trị ARV của bệnh nhân.

Chính vì vậy, chúng tôi tiến hành nghiên cứu này nhằm mục tiêu: "Mô tả thực trạng tuân thủ điều trị ARV và một số yếu tố liên quan đến tuân thủ điều trị ở trẻ HIV/AIDS tại phòng khám ngoại trú Bệnh viện Nhi Trung ương".

\section{2. Đối tượng và phương pháp}

\section{1. Đối tượng nghiên cúu}

\subsubsection{Tiêu chuẩn lựa chọn}

Trẻ HIV/AIDS từ 1 tháng tuổi đến 16 tuổi đang điều trị $A R V$ với thời gian từ 3 tháng trở lên. Đối tượng là người chăm sóc chính của trẻ đang điều trị ARV tại phòng khám hợp tác và đồng ý trả lời bộ câu hỏi phỏng vấn.

\subsubsection{Tiêu chuẩn loại trừ}

Không phải là người chăm sóc chính. Không đồng ý trả lời bộ câu hỏi phỏng vấn. Trẻ được điều trị thuốc $\mathrm{ARV}$ có thời gian dưới 3 tháng.

\subsection{Thời gian và địa điểm nghiên cưu}

Nghiên cứu được tiến hành từ tháng 01/01/2019 - 30/10/2019 tại phòng khám ngoại trú Trung tâm $\mathrm{Y}$ học lâm sàng bệnh nhiệt đới trẻ em- Bệnh viện Nhi Trung ương.

\subsection{Thiết kế nghiên cưu}

Nghiên cứu được thiết kế là mô tả cắt ngang, có phân tích.

\subsection{Cỡ mẫu và cách chon mẫu}

\subsubsection{Cỡ mẫu}

Cỡ mẫu được tính theo công thức cho nghiên cứu mô tả như sau:

$$
n=Z_{1-\alpha / 2}^{2} \frac{p(1-p)}{d^{2}}
$$

Trong đó, n: Số lượng người chăm sóc chính, cũng là số trẻ nhiễm HIV điều trị ngoại trú. p: Tỷ lệ ước tính tuân thủ điều trị ARV tốt; giá trị $\mathrm{p}$ được lấy theo nghiên cứu của tác giả Đoàn Thị Thùy Linh (năm 2011) là $78,9 \%$. d: Khoảng sai lệch mong muốn, $\mathrm{d}=\varepsilon \mathrm{p}$, lấy $\varepsilon=0,1$. Độ tin cậy $99 \%$ thì $\alpha=0,01 \Rightarrow Z_{(1-\alpha / 2)}=2,58$.Cõ̃ mẫu tính được bao gồm 185 trẻ và cũng bao gồm 185 người chăm sóc chính cho trẻ. Cộng thêm $10 \%$ dự kiến trẻ không hợp tác, số mẫu là 205. Thực tế trong 6 tháng đầu năm 2019 chúng tôi lấy được 219 trẻ HIV điều trị ngoại trú để nghiên cứu.

2.4.2. Cách chọn mẫu

Cách chọn mẫu thuận tiện, lấy lần lượt trẻnhiễm HIV đang điều trị ARV tại phòng khám ngoại trú Trung tâm $Y$ học lâm sàng bệnh nhiệt đới trẻ em- Bệnh viện Nhi Trung ương cho đến khi đủ số lượng mẫu.

2.5. Nhĩng tiêu chuẩn, chỉ tiêu sử dụng trong nghiên cúu

Phân chia nhóm tuổi: Theo cách phân chia thông thường trong nghiên cứu nhi khoa, gồm $<1$ tuồi; $1-<3$ tuổi; $3-<5$ tuổi; $5-<10$ tuổi và $10-<16$ tuổi.

Xác định tình trạng dinh dưỡng dựa vào cân nặng và chiều cao của trẻ bệnh và phân loại theo chuẩn tăng trưởng của $\mathrm{WHO}$, gồm các tình trạng: Bình thường; nhẹ cân; gầy còm; thấp còi; thừa cân, béo phì.

Xác định có bệnh kèm theo theo kết quả khám và chẩn đoán của bác sĩ

Giai đoạn bệnh: Theo Hướng dẫn chẩn đoán, điều trị HIV/AIDS - Bộ y tế.

Tuân thủ điều trị thuốc $A R V$ là việc người bệnh uống đúng thuốc, đúng liều, đúng giờ, đúng cách theo chỉ định của bác sỹ, đến khám và làm xét nghiệm theo lịch hẹn. Không đúng 1 trong các điều kiện trên là không tuân thủ điều trị. Việc tuân thủ và 
không tuân thủ điều trị của trẻ bệnh được xác định theo tiêu chuẩn của $\mathrm{WHO}$ và theo hướng dẫn của BYT.

Phương pháp và công cụ thu thập số liệu: Thu thập thông tin định lượng bằng cách sử dụng bộ câu hỏi được thiết kế sẵn để phỏng vấn người chăm sóc trẻ. Với trẻ từ 8 tuổi, nếu có thể trả lời sẽ phỏng vấn trực tiếp trẻ. Lấy thông tin thứ cấp từ hồ sơ bệnh án điều trị ngoại trú của từng trẻ sử dụng phiếu thu thập thông tin thứ cấp theo mẫu thống nhất.

\subsection{Xủ lý và phân tích số liệu}

Số liệu được xử lý trên phần mềm Stata 14.1 (StataCorp). Sử dụng phương pháp thống kê mô tả và phân tích, kết quả được trình bày dưới dạng tần số, tỷ lệ $\%$, giá trị trung bình. Phân tích yếu tố liên quan dựa vào các chỉ số: Tỷ suất chênh OR (Odd ratio), khoảng tin cậy $\mathrm{CI}, 95 \%$ và giá trị "p". Hồi quy đa biến Logistic được áp dụng để xác định các yếu tố liên quan đến tuân thủ điều trị của trẻ. Số liệu thu thập được mã hóa, bảo mật và chỉ phục vụ phân tích cho nghiên cứu.

\section{7. Đạo đức nghiên cúu}

Nghiên cứu tìm ra các yếu tố ảnh hưởng đến tuân thủ điều trị giúp nhân viên y tế giải quyết vấn đề tốt hơn và không ảnh hưởng gì đến trẻ và gia đình. Nghiên cứu được hội đồng đạo đức nghiên cứu $\mathrm{y}$ sinh Bệnh viện Nhi Trung ương phê duyệt.

\section{Kết quả}

Bảng 1. Tuổi và giới tính của trẻ HIV/AIDS trong NC $(\mathrm{n}=219)$

\begin{tabular}{|l|c|c|c|c|c|c|}
\hline \multirow{2}{*}{ Nhóm tuổi } & \multicolumn{2}{|c|}{ Trẻ trai } & \multicolumn{2}{c|}{ Trẻ gái } & \multicolumn{2}{c|}{ Chung } \\
\cline { 2 - 7 } & Số BN & Tỷ lệ \% & $\begin{array}{c}\text { Số } \\
\text { BN }\end{array}$ & Tỷ lệ \% & Số BN & Tỷ lệ \% \\
\hline$<1$ tuổi & 2 & 1,7 & 5 & 4,9 & 7 & 3,2 \\
\hline $1-<3$ tuổi & 2 & 1,7 & 5 & 4,9 & 7 & 3,2 \\
\hline $3-<5$ tuổi & 6 & 6,1 & 5 & 4,9 & 11 & 5,0 \\
\hline $5-<10$ tuổi & 36 & 30,8 & 21 & 20,6 & 57 & 26,0 \\
\hline $10-<16$ tuổi & 71 & 60,7 & 66 & 64,7 & 137 & 62,6 \\
\hline Tuổi trung bình & \multicolumn{7}{|c|}{$9,2 \pm 3,2$} \\
\hline Tổng số & 117 & 53,4 & 102 & 46,6 & 219 & 100,0 \\
\hline
\end{tabular}

Tỷ lệ trẻ theo giới gần tương đương nhau, trẻnam chiếm $53,4 \%$ và trẻ nữ chiếm $46,6 \%$. Tỷ lệ trẻ tăng dần theo nhóm tuổi, thấp nhất nhóm dưới 1 tuổi (chiếm 3,2\%) và cao nhất nhóm trẻ bệnh từ 10-16 tuối chiểm tới $62,6 \%$. Tại các nhóm tuổi, tỷ lệ trẻ là nữ cao hơn nam. Sự khác biệt không có ý nghĩa thống kê $(p>0,05)$.

Bảng 2. Tuân thủ điều trị ARV của trẻ HIV/AIDS $(\mathrm{n}=219)$

\begin{tabular}{|c|c|c|}
\hline Tuân thủ điều trị & Số lượng trẻ & Tỷ lệ \% \\
\hline Tuân thủ dùng thuốc $(\mathrm{n}=219)$ & 174 & 79,5 \\
\hline Tuân thủ tái khám $(\mathrm{n}=219)$ & 207 & 94,5 \\
\hline Tuân thủ xét nghiệm $(\mathrm{n}=219)$ & 217 & 99,1 \\
\hline Tuân thủ điều trị chung & 138 & 63,0 \\
\hline Không tuân thủ điều trị & 81 & 37,0 \\
\hline Tổng & 219 & 100,0 \\
\hline
\end{tabular}


Bảng 3. Mối liên quan giữa yếu tố ở trẻ và người chăm sóc chính đối với tuân thủ điều trị ở trẻ $(\mathrm{n}=219)$

\begin{tabular}{|c|c|c|c|c|c|c|}
\hline \multirow{2}{*}{ Tuổi } & \multicolumn{2}{|c|}{$\begin{array}{l}\text { Không tuân } \\
\text { thủ ĐT }\end{array}$} & \multicolumn{2}{|c|}{ Tuân thủ ĐT } & \multirow{2}{*}{$\begin{array}{c}\text { OR } \\
95 \% \mathrm{CI}\end{array}$} & \multirow{2}{*}{$\mathrm{P}$} \\
\hline & SL & $\%$ & SL & $\%$ & & \\
\hline$\geq 10$ tuổi & 56 & 40,9 & 81 & 51,1 & \multirow{2}{*}{$\begin{array}{c}1,57 \\
0,85-2,95 \\
\end{array}$} & \multirow{2}{*}{0,123} \\
\hline$<10$ tuồi & 25 & 30,5 & 57 & 69,5 & & \\
\hline \multicolumn{7}{|c|}{ Thời gian điều trị } \\
\hline$<1$ năm & 9 & 90,0 & 1 & 10,0 & \multirow{2}{*}{$\begin{array}{c}17,1 \\
2,26-75,5 \\
\end{array}$} & \multirow{2}{*}{$<0,01$} \\
\hline$\geq 1$ năm & 72 & 34,4 & 137 & 65,6 & & \\
\hline \multicolumn{7}{|c|}{ Số lần uống ARV mỗi ngày } \\
\hline 2 lần & 72 & 36,5 & 125 & 63,5 & \multirow{2}{*}{$\begin{array}{c}0,83 \\
0,31-2,32 \\
\end{array}$} & \multirow{2}{*}{0,687} \\
\hline 1 lần & 9 & 40,9 & 13 & 59,1 & & \\
\hline \multicolumn{7}{|c|}{ Thời gian chờ lấy thuốc } \\
\hline Quá dài & 44 & 84,6 & 8 & 15,4 & \multirow{2}{*}{$\begin{array}{c}19,3 \\
7,9-50,9\end{array}$} & \multirow{2}{*}{$<0,01$} \\
\hline Không dài & 37 & 22,2 & 130 & 77,8 & & \\
\hline \multicolumn{7}{|c|}{ Tuổi người chăm sóc chính } \\
\hline$\geq 50$ tuổi & 67 & 82,7 & 14 & 17,3 & \multirow{2}{*}{$\begin{array}{c}42,3 \\
17,9-120,1 \\
\end{array}$} & \multirow{2}{*}{$<0,01$} \\
\hline$<50$ tuổi & 14 & 10,1 & 124 & 89,9 & & \\
\hline \multicolumn{7}{|c|}{ Quan hệ của người chăm sóc chính với bệnh nhi } \\
\hline Không phải bố, me, ông bà & 22 & 44,9 & 27 & 55,1 & \multirow{2}{*}{$\begin{array}{c}1,53 \\
0,75-3,06 \\
\end{array}$} & \multirow{2}{*}{0,192} \\
\hline Là bố, mẹ, ông, bà & 59 & 34,7 & 111 & 65,3 & & \\
\hline \multicolumn{7}{|c|}{ Học vấn của người chăm sóc chính } \\
\hline Chưa tốt nghiệp THPT & 44 & 34,4 & 74 & 65,6 & \multirow{2}{*}{$\begin{array}{c}1,02 \\
0,57-1,85 \\
\end{array}$} & \multirow{2}{*}{0,920} \\
\hline$\geq$ THPT & 37 & 36,6 & 64 & 63,4 & & \\
\hline \multicolumn{7}{|c|}{ Nghề nghiệp của người chăm sóc chính } \\
\hline Nông dân, công nhân và nghề khác & 79 & 39,9 & 119 & 60,1 & \multirow{2}{*}{$\begin{array}{c}3,5 \\
0,53-12,9 \\
\end{array}$} & \multirow[b]{2}{*}{0,535} \\
\hline Cán bộ, công chức, viên chức & 2 & 9,5 & 19 & 90,5 & & \\
\hline \multicolumn{7}{|c|}{ Tình trạng hôn nhân của người chăm sóc chính } \\
\hline Đọc thân, li thân, li dị & 42 & 45,2 & 51 & 54,8 & 1,03 & 0245 \\
\hline Kết hôn và sống cùng GĐ & 39 & 30,9 & 87 & 69,1 & $0,51-3,72$ & $0,24 J$ \\
\hline Tình trạng & iiễm & của r & rời ch & sóc cl & & \\
\hline Có nhiễm & 12 & 36,4 & 21 & 63,6 & 0,96 & 0035 \\
\hline Không nhiễm & 69 & 37,1 & 117 & 62,9 & $0,40-2,21$ & U,У \\
\hline & ng cá & từ nhà & i bệnh & & & \\
\hline$\geq 100 \mathrm{~km}$ & 18 & 47,4 & 20 & 52,6 & 1,68 & 0145 \\
\hline Dưới 100 km & 63 & 34,8 & 118 & 65,2 & $0,77-3,62$ & $0,1+3$ \\
\hline
\end{tabular}

Các yếu tố liên quan đến sự không tuân thủ điều trị của trẻ HIV bao gồm thời gian điều trị ngắn dưới 1 năm, thời gian chờ đợi lấy thuốc quá dài, và người chăm sóc chính có tuổi $\geq 50$. 


\section{Bàn luận}

Khảo sát 219 trẻ chúng tôi thấy tỷ lệ tuân thủ điều trị chiếm $63 \%$, tỷ lệ này là thấp và ảnh hưởng nhiều tới kêt quả điều trị và tiến triển của trẻ bệnh. Tỷ lệ tuân thủ điều trị trong nghiên cứu của chúng tôi thấp hơn so với các nghiên cứu trước đó, $75,1 \%$ tại Hà Nội và $71,0 \%$ tại Hải Dương [4]. Phân tích số liệu thu được nhằm tìm yếu tố liên quan tới tình trạng tuân thủ điều trị dựa trên 2 nhóm vấn đề từ trẻ bệnh và người chăm sóc chính. Tỷ suất chênh của việc tuân thủ điều trị cao hơn 17 lần ở các trẻcó thời gian dùng thuốc trên 12 tháng so với các trẻcó thời gian dùng thuốc dưới 12 tháng $(\mathrm{p}<0,05)$. Chúng tôi cho rằng có nhiều lý do phù hợp để giải thích cho kết quả này. Có thể do thời gian điều trị lâu hơn giúp trẻ và gia đình thấy được hiệu quả của thuốc cũng như tiếp cận với truyền thông tốt hơn. Ngoài ra, có thể những người điều trị dưới 12 tháng, bao gồm những người mới điều trị có thể đang chủ quan và chưa nhận thức đầy đủ về hiệu quả của việc điều trị ARV. Các biện pháp tiếp cận cụ thể đối với từng cá nhân đã nhiễm HIV/AIDS là cần thiết để có thể cung cấp cho họ đầy đủ kiến thức tốt nhất về việc tuân thủ điều trị $\mathrm{ARV}$. Kết quả của chúng tôi phù hợp với kết quả của tác giả của tác giả Nguyễn Thị Xuyên và tác giả Nguyễn Ngọc Quý [5], [6]. Ngoài ra, khi sử dụng mô hình hồi quy đa biến logistics, yếu tố được báo cáo là có liên quan đến tuân thủ điều trị ở trẻlà tuổi của người chăm sóc chính. Giải thích cho kết quả này có thể do những người dưới 50 tuổi thường có địa vị xã hội cũng như giáo dục tốt hơn trong môi trường hiện đại ngày nay, do đó nhận thức của họ tốt hơn để hiểu về vai trò quan trọng của việc tuân thủ điều trị ARV đối với người đã nhiễm HIV/AIDS. Các biện pháp tiếp cận cụ thể đối với từng cá nhân đã nhiễm HIV/AIDS là cần thiết để có thể cung cấp cho họ đầy đủ kiến thức tốt nhất về việc tuân thủ điều trị ARV [6-8]. Bên cạnh đó, chúng tôi cũng nhận thấy rằng thời gian chờ thuốc không dài thì tuân thủ điều trị gấp 19,3 (95\%CI: 7,9-50,9) lần so với nhóm có thời gian chờ đợi thuốc dài. Giải thích cho điều này có thể do tâm lý của gia đình trẻ điều trị HIV, cũng như tâm lý chung của người Việt là mong muốn sự nhanh chóng và thuận tiện.

Một nghiên cứu gần đây của tác giả Trần Xuân Bách [9] đã chỉ ra, tình trạng công việc, tình trạng hôn nhân, khu vực sinh sống, thu nhập và tình trạng miễn dịch liên quan có ý nghĩa đối với không tuân thủ điều trị. Thực tế, nhiều yếu tố có ý nghĩa trong mô hình được tìm ra bởi tác giả bởi tính chất rộng lớn và đại diện của cỡ mẫu, cụ thể, tác giả đã thực hiện trên đối tượng là những người đang điều trị $\mathrm{ARV}$ tại 7 bệnh viện và trung tâm y tế cung cấp dịch vụ điều trị bằng thuốc kháng vi-rút tại ba tỉnh, bao gồm Hà Nội, Hải Phòng và Thành phố Hồ Chí Minh.

Nghiên cứu này sử dụng cả hai nguồn số liệu sơ cấp (phỏng vấn trực tiếp) và thứ cấp (hồ sơ bệnh án của bệnh nhân), do vậy thông tin thu thập được có thể bổ trợ cho nhau, qua đó nhìn nhận một cách toàn diện tình hình chăm sóc, điều trị tại phòng khám ngoại trú tại Bệnh viện Nhi Trung ương, tỷ lệ tuân thủ điều trị và các yếu tố ảnh hưởng để từ đó đưa ra được các biện pháp can thiệp, cũng như cải tiến thiết thực nhất. Phương pháp phỏng vấn trực tiếp đối với người chăm sóc chính của trẻ, kết hợp được sử dụng trong nghiên cứu có ưu điểm giúp người chăm sóc chính của trẻ dễ dàng chia sẻ hơn trong việc trao đổi thông tin về việc uống thuốc hay các hành vi cá nhân khác của trẻ, phương pháp phỏng vấn trực tiếp giúp hạn chế được khả năng đối tượng không hiểu hay không biết mà cứ khoanh vào tất cả các nội dung theo yêu cầu của 
người bên cạnh hoặc một người tự điền nhiều phiếu. Hơn nữa điều tra viên là người trực tiếp làm nghiên cứu, làm việc tại trung tâm y học lâm sàng các bệnh nhiệt đới trẻ em có kinh nghiệm trong điều tra nghiên cứu HIV/AIDS nên các thông tin thu được đảm bảo tính khách quan và sát thực hơn.

\section{Kết luận}

Chúng tôi nhận thấy tỷ lệ tuân thủ điều trị của trẻ HIV/AIDS là $63 \%$. Điều dưỡng làm việc tại phòng khám ngoại trú trung tâm Y học lâm sàng các bệnh nhiệt đới trẻ em cần chú ý tư vấn thêm cho trẻ HIV/AIDS và gia đình trẻ về tầm quan trọng của việc tuân thủ điều trị. Từ kết quả phân tích hồi quy đa biến logistics, chúng tôi khuyến cáo tập trung các mô hình can thiệp tư vấn cho trẻ mới mắc, thời gian điều trị còn dưới 1 năm và bệnh nhi có người chăm sóc chính trên 50 tuổi để nâng cao tỷ lệ tuân thủ điều trị thuốc.

\section{Tài liệu tham khảo}

[1] Hanh PTV. Study on some clinical and laboratory epidemiological factors in children infected with HIV/AIDS at the Vietnam National Children's Hospital and Hai Phong Children's Hospital. Thesis Specialist Level II, Hanoi Medical University; 2004. (in Vietnamese)

[2] Xuyen NT. Survey of patients' use of ARV drugs and adherence to treatment at outpatient HIV / AIDS treatment clinics, Bac Giang Center for Disease Control. Thesis
Specialized Pharmacist Level I. Hanoi University of Pharmacy; 2017. (in Vietnamese)

[3] Hoa MD, Cuong PV. ART adherence among people living with HIV/AIDS in Ha Noi and Hai Duong: situation and associated factors. J Pract Med Hanoi 2011;242\&243:5.

[4] Quy NN. Survey on ARV use and treatment compliance of patients in outpatient clinics for HIV / AIDS Tran Yen Medical Center Yen Bai, Thesis of Specialized Pharmacist Level I. Hanoi University of Pharmacy; 2018. (in Vietnamese)

[5] Biadgilign S, Amare D, Amberbir A et al. Adherence to highly active antiretroviral therapy and its correlates among HIV infected pediatric patients in Ethiopia. BMC Pediatrics 2008;8:53. https://doi.org /10.1186/1471-2431-8-53

[6] Davies MA, Boulle A, Fakir $\mathrm{T}$ et al. Adherence to antiretroviral therapy in young children in Cape Town, South Africa, measured by medication return and caregiver self-report: aprospective cohort study. BMC pediatrics 2008;8:34. https:// doi.org/10. 1186/1471-2431-8-34

[7] Goldman JD, Cantrell RA, Mulenga LB et al. Simple adherence Assessments to predict Virologic Failure among HIV-infected Adults with Discordant Immunologic and Clinical Responses to Antiretroviral Therapy. AIDS Res Hum Retroviruses 2008 Aug;24(8):1031-1035. https://doi.org/10.10 89/aid.2008.0035.

[8] Bach TX, Long NT, Nga NH et al. Determinants of antiretroviral treatment adherence among HIV/AIDS patients: a multisite study. Glob Health Action. 2013;6:19570. https://doi.org/10.3402/gha. v6i0.19570. 